\title{
PEMANFAATAN AGEN CERDAS UNTUK MENGUKUR PRESTASI KERJA PEGAWAI NEGERI SIPIL (PNS) (THE USE OF INTELLIGENT AGENS FOR MEASURE THE WORKING PERFOMANCE OF CIVIL SERVANTS)
}

\author{
Andri Pranolo \\ Jurusan Teknik Informatika \\ Fakultas Teknologi Industri, Universitas Ahmad Dahlan \\ Kampus 3 UAD, JI. Prof. Dr. Soepomo, SH., Janturan, Umbulharjo \\ Yogyakarta - Indonesia. \\ email : andri.pranolo@tif.uad.ac.id
}

\begin{abstract}
To implement the governance tasks, professional, responsible, honest, and fair civil servants are needed. It can be attained through a training which is implemented based on the system of working performance and career that focuses on the system of working performance. Therefore, the appraisal of working performance is carried out to evaluate the performance of civil servants for providing guidance to the officials in the evaluation of unit and organization performance. This study aims to make intelligent agens design, so that the working units and governmental organizations can do evaluation based on the self-evaluation of their employees' working performance. It refers to the government regulation number 46 year 2011, that the appraisal of the civil servants' working performance consists of Employee's Work Goal (EWG) and Work Behavior (WB) with the percentages for each are $60 \%$ and $40 \%$. The intelligent agens that can be formed from this case consist of 1) Agen-evaluator who provides the feed back of working performance progress, 2) Agen-work planner who contributes in providing recommendation of jobs which are apropriate with the civil servants whose working performance is still low, and 3) Agen-record-of-performance who contribute in recording the performance of Civil Servants.
\end{abstract}

\section{Keywords : Civil Servants, Intelligent Agen, Self-Evaluation, Working Performance.}

Untuk melaksanakan tugas pemerintahan diperlukan PNS yang profesional, bertanggung jawab, jujur, dan adil melalui pembinaan yang dilaksanakan berdasarkan sistem prestasi kerja dan sistem karier yang dititikberatkan pada sistem prestasi kerja. Oleh karena itu, penilaian prestasi kerja dilaksanakan untuk mengevaluasi kinerja PNS yang berguna untuk memberi petunjuk bagi pejabat dalam melakukan evaluasi kinerja unit dan organisasi. Penelitian ini bertujuan untuk membuat desain intelligent agent agar unit kerja dan organisasi pemerintahan dapat melakukan evaluasi berdasarkan evaluasi diri prestasi kerja pegawainya. Mengacu pada PP No 46 Tahun 2011, bahwa penilaian prestasi kerja PNS terdiri atas Sasaran Kerja Pegawai (SKP) dan Perilaku Kerja (PK) dengan bobot prosentasi nilai masing-masing sebesar $60 \%$ dan $40 \%$. Agen cerdas yang dapat dibentuk dari kasus ini terdiri dari: 1) agent-evaluator yang bertugas memberikan feed back progess Prestasi Kerja, 2) agent-rencana-kerja berkontribusi dalam memberikan rekomendasi pekerjaan yang sesuai dengan bidang PNS yang kinerjanya masih rendah, dan 3) agen record kinerja PNS bertugas untuk menerima input kinerja PNS.

Kata kunci : PNS, Intelligent Agen, evaluasi diri, prestasi kerja.

\section{PENDAHULUAN}

Untuk melaksanakan tugas pemerintahan diperlukan Pegawai Negeri Sipil (PNS) yang profesional, bertanggung jawab, jujur, dan adil melalui pembinaan yang dilaksanakan berdasarkan sistem prestasi kerja dan sistem karier yang dititikberatkan pada sistem prestasi kerja [1]. Pelaksanaan penilaian prestasi kerja PNS, aktif diberlakukan mulai pada tanggal 1 Januari 2014 [2]. Penilaian prestasi Kerja PNS adalah suatu proses penilaian secara sistematis yang dilakukan oleh Pejabat Penilai terhadap sasaran kerja pegawai dan perilaku kerja PNS [3]. Unsur penilaian prestasi kerja PNS terdiri atas Sasaran Kerja Pegawai (SKP) dan Perilaku Kerja (PK) dengan bobot prosentase nilai masing-masing sebesar $60 \%$ dan $40 \%$ [2]. SKP setiap PNS disusun berdasarkan Rencana Kerja Tahunan (RKT) instansi. SKP memuat 
kegiatan tugas jabatan dan target yang harus dicapai dalam kurun waktu penilaian yang bersifat nyata dan dapat diukur [3]. Sedangkan penilaian perilaku kerja (PK) meliputi aspek: a) orientasi pelayanan; b) integritas; c) komitmen; d) disiplin; e) kerjasama; dan f) kepemimpinan [3].

Prestasi kerja PNS tidak akan memenuhi target yang diaharapkan apabila dalam pelaksanaanya tidak dilakukan pemantauan secara periodik. Munculnya konsep intelligent agens/ Multi agen systems telah menghimpun berbagai disiplin ilmu dalam upaya membangun sebuah apalikasi terdistribusi, cerdas, dan handal [4]. Pemanfaatan intelligent agen telah banyak dilakukan dalam berbagai bidang, diantaranya untuk membangun sebuah sistem pembelajaran [5,6], desain perilaku pembeli untuk melakukan negosiasi [7], pelayanan kelistrikan industri [8], pengubah preferensi huruf, angka, dan karakter khusus ke dalam struktur database [9].

Penelitian ini bertujuan untuk membuat desain intelligent agen sebagai saran yang dapat diimplementasikan oleh pihak terkait agar unit kerja dan organisasi pemerintahan dapat melakukan evaluasi berdasarkan evaluasi diri prestasi kerja pegawainya. Evaluasi diri yang dimaksud pada penelitian ini adalah prestasi kerja PNS dalam unsur penilaian Sasaran Kerja Pegawai (SPK), dan perilaku kerja (PK). Dengan dibangunnya system ini diharapkan control prestasi kerja PNS dapat dilaksanakan dengan optimal.

\section{TINJAUAN PUSTAKA}

A. Pegawai Negeri Sipil (PNS)

Pegawai Negeri Sipil yang selanjutnya disingkat PNS adalah Warga Negara Indonesia yang memenuhi syarat tertentu, diangkat sebagai Pegawai Aparatur Sipil Negara (ASN) secara tetap oleh pejabat pembina kepegawaian untuk menduduki jabatan pemerintahan [10].

Manajemen PNS meliputi [10]:

a. penyusunan dan penetapan kebutuhan;

b. pengadaan;

c. pangkat dan jabatan;

d. pengembangan karier;

e. pola karier;

f. promosi;

g. mutasi;

h. penilaian kinerja;

i. penggajian dan tunjangan;

j. penghargaan;

k. disiplin;

I. pemberhentian;

m. jaminan pensiun dan jaminan hari tua; dan

n. perlindungan.

Manajemen PNS pada Instansi Pusat dilaksanakan oleh pemerintah pusat dan pada Instansi Daerah dilaksanakan oleh pemerintah daerah sesuai dengan ketentuan peraturan perundangundangan [10].

\section{B. Prestasi Kerja PNS}

Penilaian prestasi kerja PNS adalah suatu proses penilaian secara sistematis yang dilakukan oleh pejabat penilai terhadap sasaran kerja pegawai dan perilaku kerja PNS berdasarkan prinsip objektif, terukur, akuntabel, partisipatif, dan trasparan [2]. Penilaian prestasi kerja teridiri dari dua unsur yaitu Sasaran Kerja Pegawai (SKP) dengan bobot penilaian 60\%, dan Perilaku Kerja bobot nilai $40 \%$.

Tatacara penilaiannya diatur tersendiri dalam Peraturan Kepala Badan Kepegawaian Negara Nomor 1 Tahun 2013 Tentang Ketentuan Pelaksanaan Peraturan Pemerintah Nomor 46 Tahun 2011 Tentang Penilaian Prestasi Kerja Pegawai Negeri Sipil.

\section{Sasaran Kerja Pegawai (SKP)}

Setiap PNS diwajibkan oleh pemerintah untuk menyusun SKP berdasarkan rencana kerja instansi tahunan atau biasa disebut dengan Recana Kerja Tahunan (RKT) [2]. SKP merupakan rencana kerja dan target yang akan dicapai oleh seorang PNS[3]. SKP merupakan salah satu unsur penilaian prestasi kerja PNS dengan bobot $60 \%$, dan lainnya $40 \%$ terdapat pada unsur perilaku kerja $[2,3]$. 
Tatacara penyusunan SKP [3] :

a. Setiap PNS wajib menyusun SKP berdasarkan RKT instansi. Dalam menyusun SKP harus memperhatikan hal-hal sebagai berikut: Jelas, dapat diukur, relevan, dapat dicapai, dan memiliki target waktu.

b. SKP memuat kegiatan tugas jabatan dan target yang harus dicapai dalam kurun waktu penilaian yang bersifat nyata dan dapat diukur. Setiap kegiatan tugas jabatan yang akan dilakukan harus didasarkan pada tugas dan fungsi, wewenang, tanggung jawab, dan uraian tugasnya yang secara umum telah ditetapkan dalam struktur organisasi dan tata kerja (SOTK).

c. SKP yang telah disusun harus disetujui dan ditetapkan oleh Pejabat Penilai sebagai kontrak kerja.

d. Dalam hal SKP yang disusun oleh PNS tidak disetujui oleh Pejabat Penilai maka keputusannya diserahkan kepada Atasan Pejabat Penilai dan bersifat final.

e. SKP ditetapkan setiap tahun pada awal Januari.

f. Dalam ha1 terjadi perpindahan pegawai setelah bulan Januari maka yang bersangkutan tetap menyusun SKP pada awal bulan sesuai dengan surat perintah melaksanakan tugas atau surat perintah menduduki jabatan.

g. PNS yang tidak menyusun SKP dijatuhi hukuman sesuai dengan

h. ketentuan peraturan perundang-undangan yang mengatur mengenai disiplin PNS.

Unsur-unsur SKP [3] :

a. Kegiatan Tugas Jabatan. Setiap kegiatan tugas jabatan yang akan dilakukan harus mengacu pada penetapan Kinerja/RKT, sebagai implementasi kebijakan dalam rangka mencapai tujuan dan sasaran organisasi yang telah ditetapkan dan harus berorientasi pada hasil secara nyata dan terukur. Dalam melaksanakan kegiatan tugas jabatan pada prinsipnya pekerjaan dibagi habis dari tingkat jabatan yang tertinggi sampai dengan tingkat jabatan yang terendah secara hierarki.

b. Angka Kredit. Satuan nilai dari tiap butir kegiatan dan/atau akumulasi nilai butir-butir kegiatan yang harus dicapai oleh seorang pejabat fungsional dalam rangka pembinaan karier yang bersangkutan ditetapkan dengan jumlah angka kredit yang akan dicapai. Oleh sebab itu pejabat fungsional tertentu harus menetapkan target angka kredit yang akan dicapai dalam 1 (satu) tahun.

c. Target, meliputi :

1) Setiap pelaksanaan kegiatan tugas jabatan harus ditetapkan target yang akan diwujudkan secara jelas, sebagai ukuran prestasi kerja. Dalam menetapkan target meliputi aspek sebagai berikut: a) Kuantitas (Target OutPut), b) Kualitas (Target Kualitas), c) Waktu (Target Waktu), d) Biaya (Target Biaya),

2) Penyusunan target SKP paling sedikit meliputi aspek kuantitas, kualitas, dan waktu sesuai dengan karakteristik, sifat, dan jenis kegiatan pada masing-masing unit kerja. Apabila kegiatan tugas jabatan tersebut dibiayai/ dianggarkan, maka dapat disertai aspek biaya dalam penyusunan SKP.

\section{Agen}

Agen adalah suatu entitas software komputer yang memungkinkan user (pengguna) untuk mendelegasikan tugas kepadanya secara mandiri (autonomously) [7] atau dengan sedikit panduan dari pengguna [11 ]. Selain itu agen juga dapat didefinisikan sesuatu yang dapat melihat lingkungan sebagai input melalui "sensor" dan memberikan respon terhadap lingkungannya melalui "tindakan/actuators" [12].

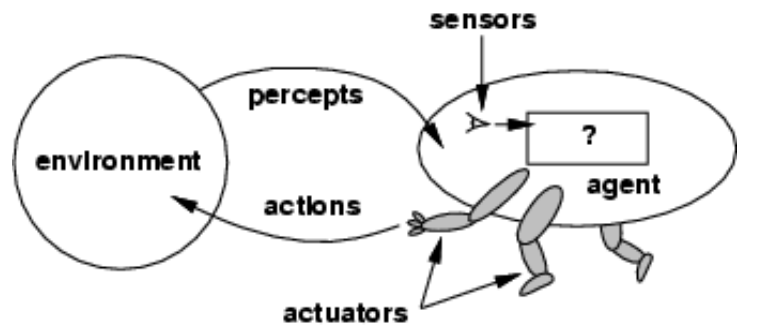

Gambar 1. Agen [12] 
Apabila dipandang dalam konsep black-box, software agen dapat diterjemahkan sebagaimana sistem, yaitu menerima input (perception) dari lingkungan, diproses pada bagian intelligent processing, dan menghasilkan output (action) [13]. Sistem Komputer (software atau hardware) dapat dikatakan sebagai agen apabila memenuhi sifat-sifat sebagai berikut [14, 15]:

(a) Autonomy (otonom). Mempunyai kontrol atas tindakannya dan dapat bekerja tanpa intervensi pengguna.

(b) Social ability (Kemampuan bersosial). dapat berkomunikasi dengan agen-agen lainnya dan/atau pengguna operator.

(c) Reactivity (reaktif). reaktif terhadap perubahan dalam lingkungannya.

(d) Pro-activeness (proaktif). kemampuan dalam mengambil inisiatif berdasarkan pada tujuan yang telah ditentukan sebelumnya.

Sifat Otonom dari sebuah agen merupakan konsep sentral, artinya bahwa agen tidak perlu menunggu untuk menerima instruksi tentang apa yang harus dilakukannya [16].

\section{E. Multi Agen systems}

Multi-agen systems (MAS) merupakan perwujudan dari paradigma distributed computing yang berdasarkan pada interaksi banyak agen yang memiliki tingkah laku cerdas [17]. Selain itu, MAS juga dapat dipandang sebagai sistem yang terdiri dari grup agen yang dapat berinteraksi satu dengan yang lainnya [14].

MAS dapat menyelesaikan suatu persoalan dengan cara pendekatan pembagian tugas/fungsi dan kerjasama antar agen untuk menghasilkan solusi yang efisien [17], atau dengan kata ain MAS menampilkan perbedaan tipe interaksi yang kompleks untuk setiap agen, dari kompetisi langsung, melalui koordinasi dan negosiasi, sampai kepada kerajasama secara menyeluruh [18].

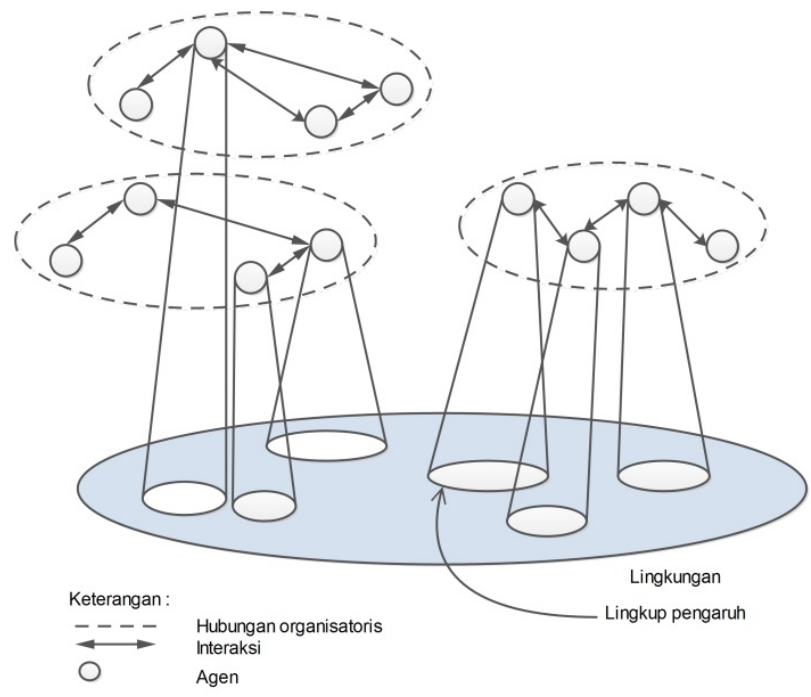

Gambar 2. Struktur multi agen system [18]

\section{METODE}

Untuk melakukan analisa, desain, dan membangun multi agen yang beragam digunakan metode Multiagen Systems Engineering (MaSE). Fokus utama metode MaSE adalah menjadi alat bantu untuk melakukan rumusan kebutuhan, analisis, desain, dan implementasi multiagen systems [4].

Metode MaSE terbagi ke dalam dua Fase, yaitu analisis dan desain. Fase analisis terdiri dari tiga kegiatan/tahapan, yaitu capturing goals (menentukan tujuan), applying use case (menerapkan use case), dan refining roles (memperjelas peran). Tujuan tahap analisis adalah untuk membuat peran dan tugas setiap bagian sistem agar sesuai dengan kebutuhan secara umum. Fase desain terdiri dari empat tahapan, yaitu creating agen class (membuat agen class), conversation construction (mengkontruksi komunikasi antar agen), assembling agen classes (membuat kelas agen), system design (desain sistem). 


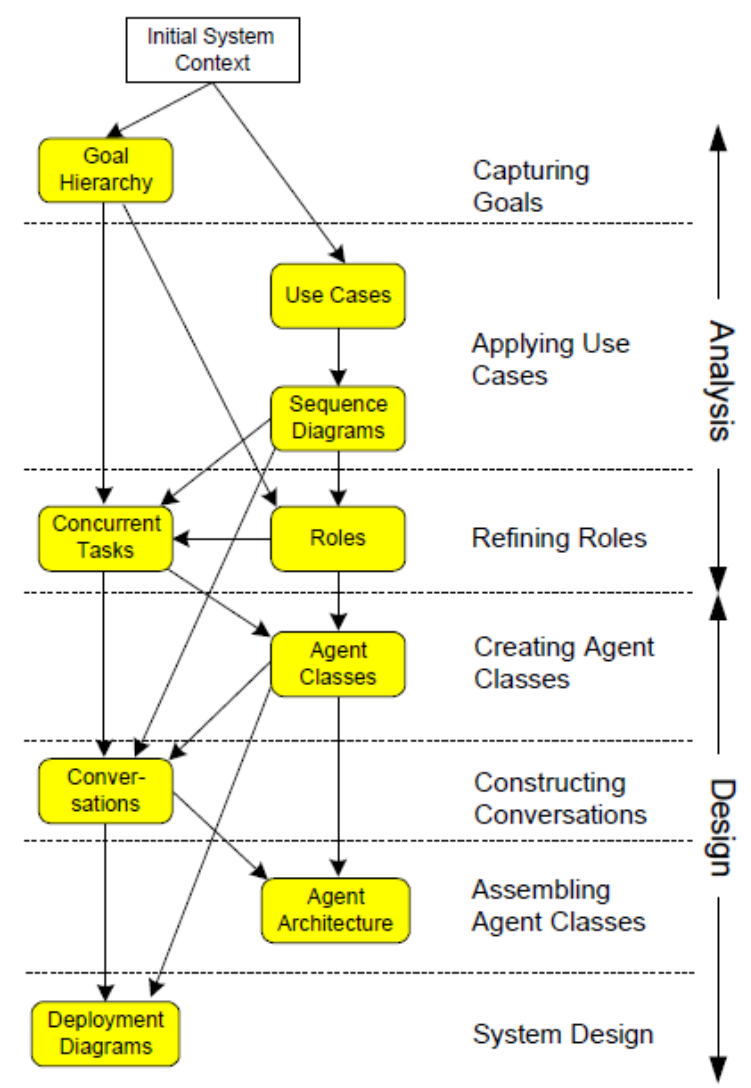

\section{Gambar 3. Tahapan Metode MaSE [4]}

\section{HASIL DAN PEMBAHASAN}

A. Arsitektur Sistem dan model role agen

Agen cerdas yang dapat dibentuk dari kasus ini terdiri dari : 1) Agen-record-kinerja yang bertugas merekam data rencana kerja dan laporan kinerja PNS; 2) Agen-evaluator yang bertugas memberikan feed back progess Prestasi Kerja; 3) dan Agen-rencana-kerja berkontribusi dalam memberikan rekomendasi pekerjaan yang sesuai dengan bidang PNS yang kinerjanya masih rendah.

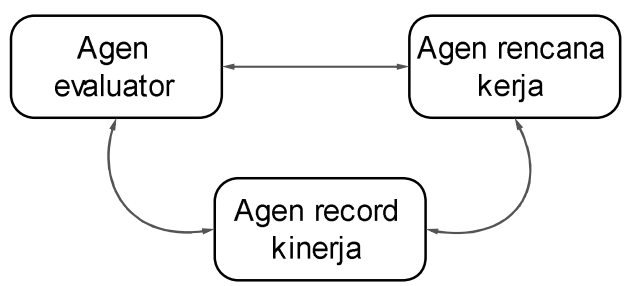

\section{Gambar 4. Arsitektur Sistem}

Arsitektur sistem yang diusulkan dapat dideskripsikan seperti tampak pada Gambar 4. Setiap agen mempunyai fungsi masing-masing yang saling berkoordinasi dan berkomunikasi dalam mencapai tujuan. Arsitektur secara detail untuk setiap agen yang mengacu kepada Lieping dkk. [20] ditunjukkan pada Gambar 5,6, dan 7. Adapun fungsi dan prosedur kerja setiap agen dapat dijelaskan sebagai berikut:

1. Agen rencana kerja

Agen rencana kerja berfungsi dalam proses pendefinisian rencana kerja. Rencana kerja merupakan rencana yang memuat kegiatan tahunan dan target yang akan dicapai sebagai penjabaran dari sasaran dan program yang telah ditetapkan oleh instansi Pemerintah [3] atau biasa disebut sebagai Penetapan Kinerja atau Rencana Kerja Tahunan (RKT). 
User berinterakasi dengan agen melalui sistem informasi manajemen, diantaranya memberikan informasi apabila ada RKT yang belum masuk dalam rencana Kegiatan Tugas Jabatan yang disusun atau tercatat pada agen record kinerja.

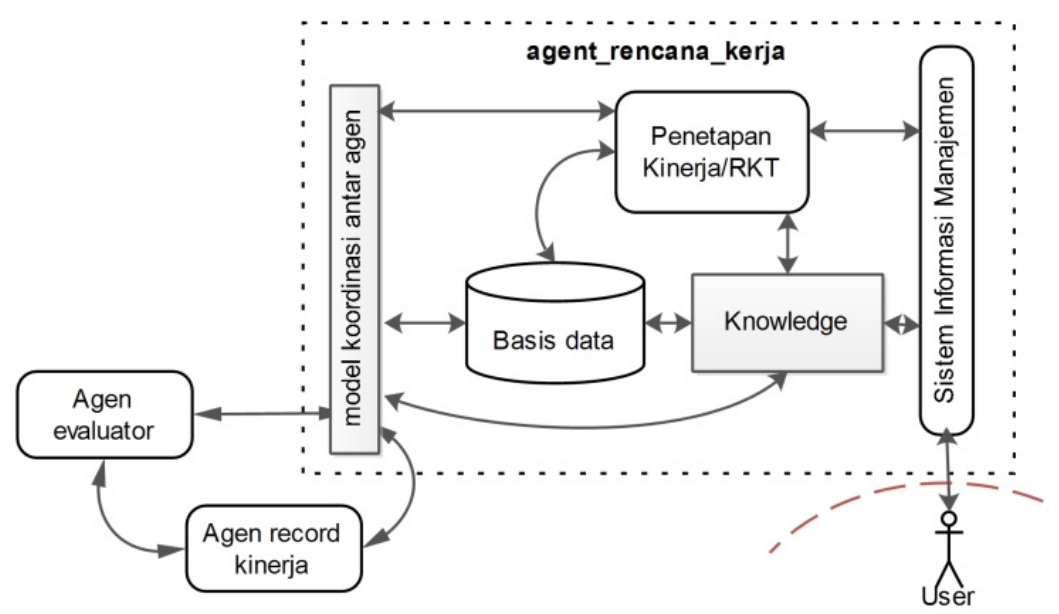

Gambar 5. Arsitektur Agen Rencana Kerja

Agen rencana kerja menyediakan daftar pekerjaan sebagai bahan penyusunan Sasaran Kerja Pegawai (SKP) dan sebagai bahan rekomendasi pekerjaan bagi pegawai yang menyusun SKP masih rendah dibandingkan yang seharusnya sesuai target yang diharapkan.

Model koordinasi antar agen yang terdapat di dalam agen rencana kerja menyatakan bagaimana agen tersebut melakukan koordinasi dengan agen lain. Basis data berisi data yang berkaitan dengan RKT dan knowledge.

\section{Agen evaluator}

Agen evaluator berfungsi untuk mengevaluasi progress SKP dan Perilaku Kerja yang terdapat pada agen record kinerja PNS. Agen evaluator dapat berkoordinasi dengan Pejabat Penilai melalui Sistem Informasi Manajemen, diantaranya ketika ada PNS yang dinilai progress SKP-nya masih di bawah standard, agen evaluator akan memberikan informasi kepada Pejabat Penilai. Pejabat penilai adalah atasan langsung PNS yang dinilai, dengan ketentuan paling rendah pejabat struktural eselon $V$ atau pejabat lain yang ditentukan [3]. Informasi lainnya adalah RKT yang belum terlaksana hasil dari komunikasi antara agen evaluator dan agen rencana kerja untuk selanjutnya oleh agen evaluator akan diteruskan kepada agen record kinerja PNS untuk diproses lebih lanjut.

Pejabat penilai juga dapat memberikan respon kepada agen evaluator tentang pilihan rekomendasi yang diberikan oleh agen evaluator. Rekomendasi yang diberikan dapat berupa pekerjaan dalam RKT yang dapat didisposisikan kepada PNS yang sesuai.

Agen evaluator melakukan penilaian Prestasi Kerja PNS dengan menggabungkan unsur SKP dan Perilaku kerja dengan bobot masing-masing 60\% (enam puluh persen) dan $40 \%$ (empat puluh persen). Selanjutnya, dilakukan penentuan kriteria Prestasi Kerja berdasarkan ketentuan sebagai berikut [2]:
a. $91 \mathrm{ke}$ atas
: sangat baik
b. $76-90$
: baik
c. $61-75$
: cukup
d. $51-60$
: kurang
e. 50 ke bawah : buruk

Unsur SKP yang diinilai berdasarkakn kriteria: kuantitas/output, kuanlitas/mutu, waktu, dan biaya. Setiap aspek dihitung berdasarkan rumus sebagai berikut [2,3]:

1) Aspek kuantitas/output (AKt),

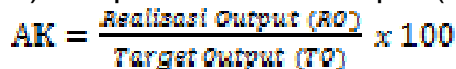

2) Aspek Kualitas/mutu (AKI),

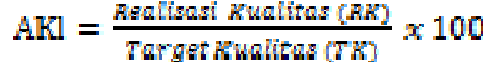


3) Aspek Waktu (AW),

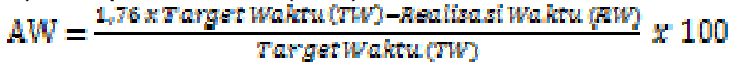

4) Aspek biaya $(A B)$,

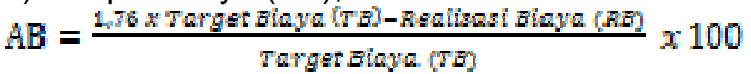

Selain itu, untuk capaian SKP aspek waktu tingkat efisiensi > 24\% (AW >24\%) diberikan nilai cukup sampai dengan buruk dengan menghitung menggunakan rumus:

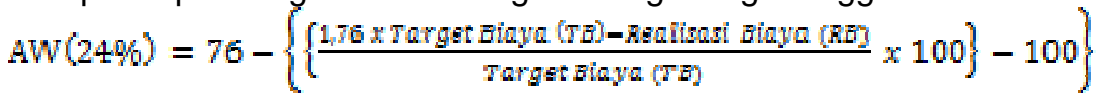

Selanjutnya, untuk menghitung presentase waktu dari target waktu perhitungannya digunakan rumus [3]:

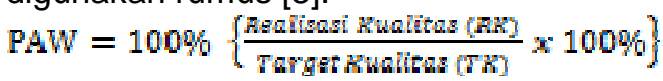

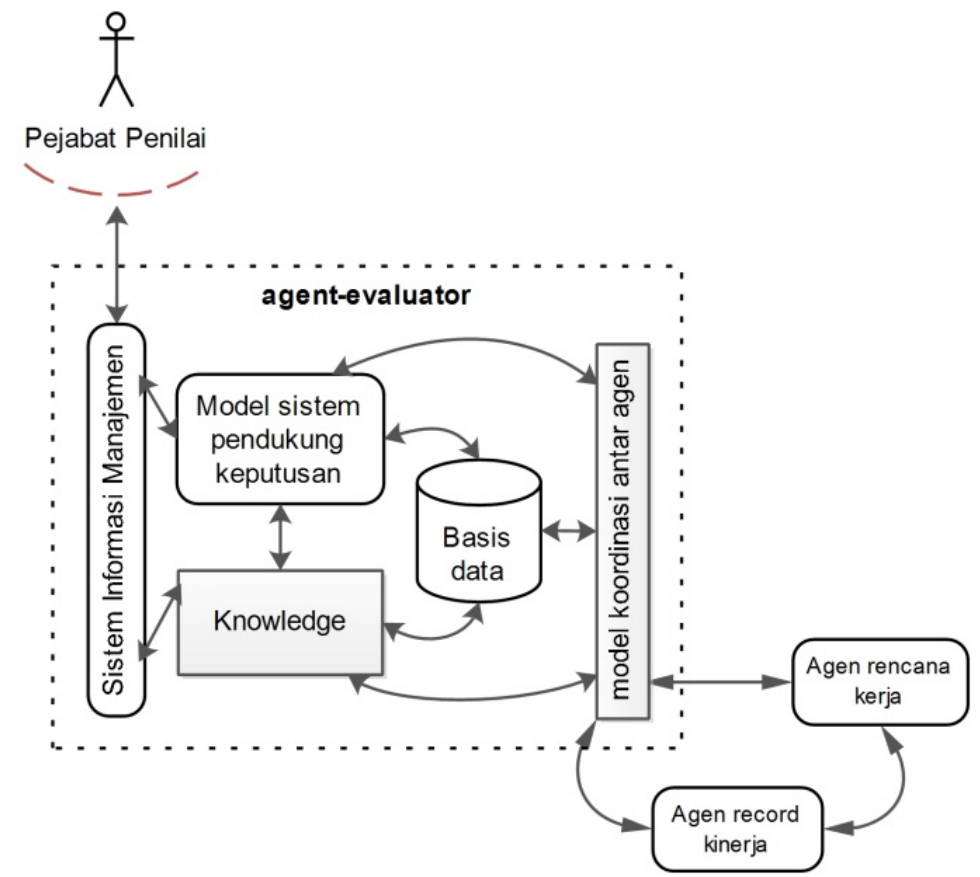

Gambar 6. Arsitektur Agen Evaluator

Unsur perilaku kerja dinilai berdasarkan kriteria : 1) orientasi pelayanan, 2) integritas, 3) komitmen, 4) disiplin, 5) kerjasama, dan 6) kepemimpinan [2,3]. Secara spesifik kriteria penilaian unsur perilaku kerja dituangkan dalam anak lampiran 1-f pada Peraturan Kepala Badan Kepegawaian Negara Nomor 1 Tahun 2013 Tentang Ketentuan Pelaksanaan Peraturan Pemerintah Nomor 46 Tahun 2011 Tentang Penilaian Prestasi Kerja Pegawai Negeri Sipil [3].

\section{Agen record kinerja PNS}

Agen record kinerja PNS berfungsi diantaranya untuk menerima informasi tentang kegiatan tugas jabatan, angka kredit, dan target. Target digunakan sebagai ukuran prestasi kerja yang meliputi aspek kuantitas (target output), aspek kualitas (target kualitas), aspek waktu (target waktu), dan aspek biaya (target biaya) [3].

Target Output (TO) dapat berupa dokumen, konsep, naskah, surat keputusan, paket, laporan, dan lain-lain. Target Kualitas (TK) harus memprediksi pada mutu hasil kerja yang terbaik, target kualitas diberikan nilai paling tinggi 100 (seratus). Target Waktu (TW) harus memperhitungkan berapa waktu yang dibutuhkan untuk menyelesaikan suatu pekerjaan, misalnya bulanan, triwulan, kwartal, semester, dan tahunan. Target Biaya (TB) harus memperhitungkan berapa biaya yang dibutuhkan untuk menyelesaikan suatu pekerjaan dalam 1 (satu) tahun, misalnya jutaan, ratusan juta, miliaran, dan lain-lain [3]. 


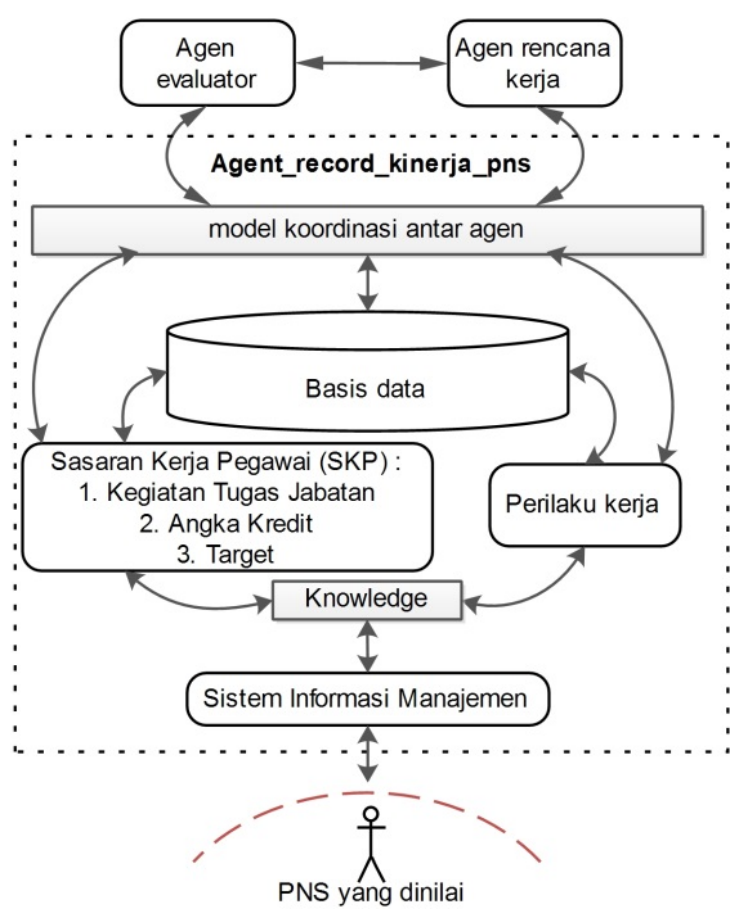

\section{Gambar 7. Arsitektur Agen Record Kinerja PNS}

PNS yang dinilai berkomunikasi dengan agen melalui sistem informasi manajemen, untuk memberikan informasi target dan capaian kinerja yang telah dilaksanakan. Selain itu juga akan memperoleh informasi perilaku kerja berdasarkan informasi yang diolah oleh agen berdasarkan laporan capaian kinerja dari PNS yang dinilai lainnya. Agen rencana kinerja PNS melakukan koordinasi dengan agen rencana kerja dalam hal panyusunan tugas jabatan, angka kredit, dan target yang harus dicapai oleh PNS, selain itu memberikan informasi rekomendasi rencana kerja yang dapat dikerjakan oleh PNS yang dinilai melalui agen record kinerja PNS.

\section{B. Komunikasi agen}

Model role mendeskripsikan peran dan posisi setiap agen di dalam sistem. Oleh karena itu, model role juga secara implisit mendefinisikan topologi pola interaksi dan kontrol dalam komunikasi antar agen di dalam sistem [21]. Komunikasi antar agen mengacu kepada Zambonelli, dkk. [21] diantaranya dapat dideskripsikan seperti pada Gambar 8.

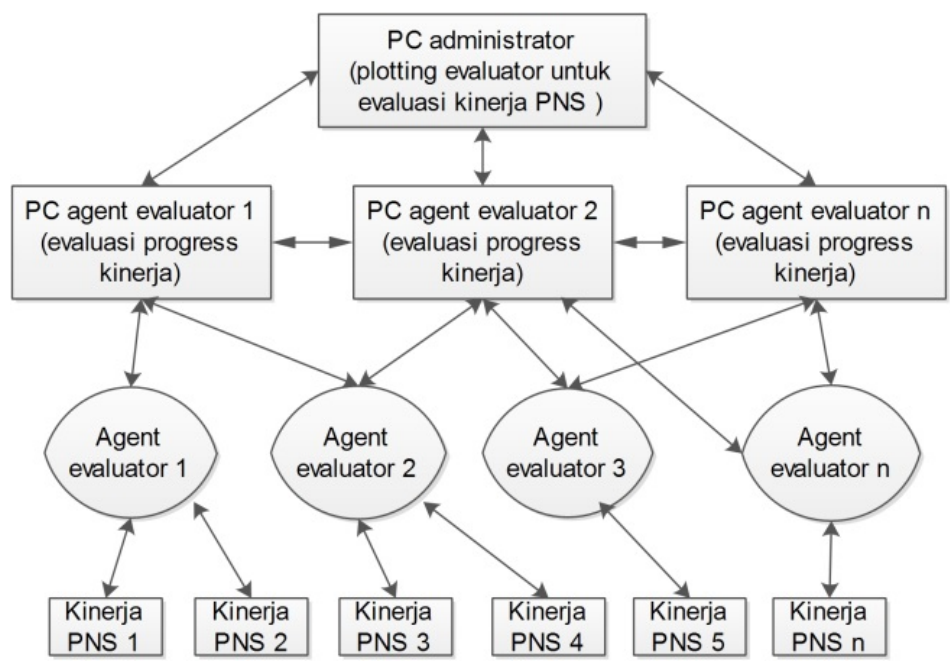

Gambar 8. Komunikasi Antar Agen 
Administrator melakukan pembagian tugas untuk mengevaluasi kinerja PNS kepada agen evaluator melalui PC Administrator. Setiap agen evaluator dapat mengevaluasi lebih dari 1 (satu) kinerja PNS berdasar tugas yang diberikan kepadanya.

Adapun algoritma untuk komunikasi antar agen dapat ditulis sebagai berikut:

a) Agen rencana kerja

1. Ambil dan simpan data rencana kerja di database

2. Cek apakah ada rencana kerja yang belum tercatat di SKP, jika ada kerjakan langkah 3 , jika tidak langsung ke langkah 6

3. Tandai rencana kerja yang telah dicatat dalam rencana SKP

4. Tampilkan dan rekomendasikan rencana kerja yang belum dicatat pada SKP

5. Kembali ke langkah 2

6. Selesai

b) Agen record kinerja PNS

1. Lihat rencana kerja

2. Catat Target output (TO), Target Kualitas (TK), Target waktu (TW), dan Target Biaya (TB)

3. Catat progress capaian TO, TK, TW, dan TB

4. Apakah periode rencana kerja masih tersedia? jika ya, kerjakan langkah 5, jika tidak kerjakan langkah 8

5. Tampilkan hasil penilaian progress dan catatan hasil evaluasi sementara

6. Tampilkan rekomendasi pekerjaan

7. Catat progress capaian TO, TK, TW, dan TB

8. Tampilkan hasil penilaian kinerja

9. Selesai

c) Agen evaluator

1. Lihat Target output (TO), Target Kualitas (TK), Target waktu (TW), dan Target Biaya (TB) pada agen record kinerja PNS

2. Lihat target progress capaian TO, TK, TW, dan TB

3. Buat prosentase capaian TO, TK, TW, dan TB

4. Catat rekomendasi apabila prosentase capaian masih jauh dari prosentase yang harus dicapai dalam periode evaluasi

5. Cek apakah masih periode jadwal evaluasi ? jika ya kerjakan langkah 1, jika tidak kerjakan langkah 6 .

6. Cek dan lakukan pencatatan perilaku kinerja

7. Hitung prestasi kinerja PNS

8. Berikan kesimpulan prestasi kerja berdasarkan kriteria : sangat baik (91 ke atas), baik (76 - 90), Cukup (61-75), Kurang (51-60), dan Buruk (50 ke bawah)

9. Tampilkan hasil evaluasi

10. Selesai

\section{KESIMPULAN}

Adapun kesimpulan dan saran pada penelitian ini sebagai berikut:

1) Agen cerdas yang dapat dibentuk untuk mengukur prestasi kerja PNS terdiri dari 3 (tiga) agen yaitu, 1) Agen-record-kinerja yang bertugas merekam data rencana kerja dan laporan kinerja PNS; 2) Agen-evaluator yang bertugas memberikan feed back progess Prestasi Kerja; 3) dan Agen-rencana-kerja berkontribusi dalam memberikan rekomendasi pekerjaan yang sesuai dengan bidang PNS yang kinerjanya masih rendah.

2) Multi agen system murapakan teknologi baru di dalam artificial intelligent. Dengan memanfaatkan intelligent agen ini dapat membantu di dalam proses evaluasi kinerja PNS, sehingga target kerja atau RKT dapat tercapai.

\section{DAFTAR PUSTKA}

[1] Undang-Undang Republik Indonesia Nomor 43 Tahun 1999 Tentang Perubahan Atas Undang-Undang Nomor 8 Tahun 1974 Tentang Pokok-Pokok Kepegawaian

[2] Peraturan Pemerintah Republik Indonesia Nomor 46 Tahun 2011 tentang Penilaian Prestasi Kerja Pegawai Negeri Sipil 
[3] Peraturan Kepala Badan Kepegawaian Negara Nomor 1 Tahun 2013 Tentang Ketentuan Pelaksanaan Peraturan Pemerintah Nomor 46 Tahun 2011 Tentang Penilaian Prestasi Kerja Pegawai Negeri Sipil

[4] Deloach, S.A., M.F. Wood, dan C.H. Sparkman. 2001. Multi agen systems engineering. International Journal of Software Engineering and Knowledge Engineering 11(3) : 231$258 \mathrm{pp}$.

[5] Lourdes, S.., L.C.A. Lilia, dan M.T. Martha. A Multi-Agen Intelligent Learning System: An Application with a Pedagogical Agen and Learning Objects. Creative Education Vol.4, No.7A2, 181-190 DOI:10.4236/ce.2013.47A2024

[6] Fontes, L.M.O. dan F.M.M. Neto. 2011. A Multiagen System to Support Problem-Based Learning. Creative Education Vol.2, No.5, 452-457

[7] awati, D. 2012. Pemodelan Matematis untuk PePespektif Perilaku Agen Cerdas Pembeli dengan Pendekatan (MOEA) NSGA II. Jurnal Link Vol 16(1) 1 - 6, ISSN 1858 4667

[8] Triwidodo, H., H. Suryoatmojo, dan M. Pujiantara. 2012. Pendekatan Adaptif Multi Agen Untuk Koordinasi Rele Proteksi Pada Sistem Kelistrikan Industri. Jurnal Teknik Pomits. Vol. 1(1): 1-6

[9] Arumugam, G. dan T.J. Devadas. 2010. Object Oriented Intelligent Multi-Agen System Data Cleaning Architecture to clean Preference based Text Data. International Journal of Computer Applications 9(8): 34-44

[10] Undang-Undang Republik Indonesia Nomor 5 Tahun 2014 Tentang Aparatur Sipil Negara

[11] Moradi, M., A. Aghaie, dan M. Hosseini. 2013. Knowledge-collector agens: Applying intelligent agens in marketing decisions with knowledge management approach. Knowledge-Based Systems 52 (2013) 181-193

[12] Russell, S., and P Norvig. 2010. Artificial Intelligence: A Modern Approach, 3rd Edition. Prentice Hall. ISBN-13: 978-0-13-606733-7

[13] Wahono, R.S. 2001. Pengantar Software Agen: Teori dan Aplikasi. Proceedings of the IECl Japan Workshop Vol. 3 No. $1:$ 4-21.

[14] Shirazi, M.A, dan J. Soroor. 2007. An intelligent agen-based architecture for strategic information system applications. Knowledge-Based Systems 20 (2007) 726-735

[15] Zhao, Q., dan S. Liu. 2011. Relay Protection Based on Multi-Agen System. pp 286-289. 978-1-4244-8165-1/11. IEEE

[16] Cavalcante, R.C., I.I. Bittencourt, A.P. da Silva, M. Silva, E. Costa, dan R. Santos. 2012. A survey of security in multi-agen systems. Expert Systems with Applications 39 (2012) 4835-4846

[17] Talia, D. 2012. Clouds Meet Agens : Toward intelligent cloud services. IEEE Internet Computing $78-81$

[18] Verbrugge, R. 2009. Logic and social cognition : The Facts Matter, and so do Computational Models. J Philos Logic (2009) 38:649-680

[19] Wooldridge, M. 2002. An introduction to multiagen systems. John Wiley \& Sons Ltd, England.

[20] Lieping, Z., dan Z. Yunsheng. 2010. Research on Hierarchical Distributed Coordination Control in Process Industry Based on Multi-Agen System. 2010 International Conference on Measuring Technology and Mechatronics Automation. pp 96-100. DOI 10.1109/ICMTMA.2010.683

[21] Zambonelli, F., N.R. Jennings., dan M. Wooldridge. 2003. Developing Multiagen Systems: The Gaia Methodology. ACM Transactions on Software Engineering and Methodology, Vol. 12, No. 3, July 2003, pp. 317-370. 